\title{
A criança e o menor: a escolarização das crianças sob tutela do Estado, em Juiz de Fora/MG (1888-1916)
}

\author{
Child and minor: schooling of orphan under State \\ guardianship, in Juiz de Fora /Mg) (1888-1916) \\ El niño y el menor: escolarización de los niños \\ huérfanos tutelados por el Estado en Juiz de Fora/mg \\ (1888-1916) \\ PALOMA REZENDE DE OLIVEIRA \\ Universidade do estado de Minas GERAIS, CARANGOla, MG, Brasil \\ DOUTORA EM EDUCAÇ̃̃o \\ E-MAIL: PALOMA.OLIVEIRA@UEMG.BR
}

\section{Resumo}

0 presente estudo tem por objetivo analisar como se deu o processo de escolarização das crianças sob tutela do Estado, no contexto de Juiz de Fora/MG (1888 -1916). As relações estabelecidas entre os atores da época, bem como a materialização de suas ações, indicaram distintas concepções de infância e diferentes formas de escolarização naquele contexto. A partir da análise das fontes levantadas no Arquivo Municipal de Juiz de Fora, os casos de tutela e curatela do período de (1888-1896), foi possível constatar que havia ainda uma distinção em relação ao tipo de educação oferecida às crianças órfãs, conforme sua origem social. Buscou-se, então, mapear as práticas e os discursos presentes nos documentos para, a partir daí, estabelecer relações entre o contexto local e aspectos do contexto mais amplo, o qual tinha a civilização da sociedade e, em especial, das crianças, por meio da escolarização, como um projeto da modernidade (BOTO, 2003; GREIVE, 2019; FARIA FILHO, 2000). A análise dos discursos normativos e das práticas educacionais 
tomou como base os debates teóricos e metodológicos acerca da cultura e da forma escolar (FELGUEIRAS, 2010; VIDAL, 2010; VINCENT, 1994; JULIA, 2001 e CHARTIER, 2009), indicando modelos de educação distintos para as crianças órfãs, conforme sua classe social, bem como apontamentos sobre seu cotidiano.

Palavras-chave: Escolarização. Infância. Órfãos. Tutela do Estado.

\begin{abstract}
This study aims to analyze the process of schooling of children under state guardianship, in the context of Juiz de Fora / MG (1888 -1916). The relationships established between the actors and the materialization of their actions indicated different conceptions of childhood and different forms of education in that context. From Juiz de Fora city hall files analysis, the guardianship and curatela cases from the period of (1888-1896) - it was possible to verify that there was a distinction of the education type offered to orphan children, according to their social origin. The mapping of the practices and discourses present in the documents allowed establishing relationships between the local context and aspects of the national context, which had the civilization of society and especially children through the school as a modernization project (BOTO, 2003; GREIVE, 2019; FARIA FILHO, 2000). The analysis of normative discourses and educational practices was based on theoretical / methodological debates about school culture and school form (FELGUEIRAS, 2010; VIDAL, 2010; VINCENT, 1994; JULIA, 2001 and CHARTIER, 2009), indicating children's family education model in different social categories and notes on their daily lives.
\end{abstract}

Keywords: Schooling. Childhood. Orphans. State Guardianship.

\title{
Resumen
}

El presente estudio tiene como objetivo analizar cómo se llevó a cabo el proceso de escolarización de los niños bajo la tutela estatal, en el contexto de Juiz de Fora / MG (18881916). Las relaciones establecidas entre los actores de la época, así como la materialización de sus acciones, indicaron diferentes concepciones de la infancia y diferentes formas de escolarización en ese contexto. A partir del análisis de los casos de tutela y curatela del período de (1888-1896) en el Archivo Municipal de Juiz de Fora, fue posible verificar que aún existía una distinción con respecto al tipo de educación ofrecida a los niños huérfanos, de acuerdo con su origen social. Luego se buscó mapear las prácticas y discursos presentes en los documentos para, a partir de ahí, establecer relaciones entre el contexto local y los aspectos del contexto más amplio, que tenía la civilización de la sociedad y especialmente de los niños, a través de la escuela como proyecto de modernidad (BOTO, 2003; GREIVE, 2019; FARIA FILHO, 2000). El análisis de los discursos normativos y las prácticas educativas se basó en debates teóricos y metodológicos sobre cultura y forma escolar (FELGUEIRAS, 2010; VIDAL, 2010; VINCENT, 1994; JULIA, 2001 y CHARTIER, 2009), indicando modelos de 
educación para niños huérfanos de acuerdo con su clase social, así como notas sobre su vida cotidiana.

Palabras clave: Escolarización. Infancia. Huérfanos. Tutela estatal.

\section{Introdução}

Analisar como se deu o processo de escolarização das crianças sob tutela do Estado, no contexto de Juiz de Fora/MG (1888 -1916), requer, primeiramente, trazer à tona uma reflexão sobre como as políticas de assistência à infância, vinculadas à escolaridade, foram tratadas pela historiografia brasileira.

A partir do levantamento das atas da Câmara Municipal de Juiz de Fora, de cerca de 20 casos de tutela e curatela do período de (1888-1896) e dos documentos das escolas paroquiais, que constituem o acervo do Arquivo Municipal de Juiz de Fora, foi possível constatar que havia uma distinção em relação ao tipo de escolarização oferecida à criança sob tutela, conforme sua origem social. E ainda, que as relações estabelecidas entre os atores da época, bem como a materialização de suas ações expressavam distintas concepções de infância e de escolarização.

Ao analisarmos esses documentos produzidos em um momento histórico distinto do atual foi preciso interrogar inicialmente sobre suas condições de produção, circulação e recepção, que informam sua estrutura textual de modo a sustentar as estratégias interpretativas.

Embora nenhum documento possa ser tomado como expressão direta da realidade, os textos arquivísticos, em geral, constituíram-se como documentos que buscavam expressar determinada verdade ou produzi-la. Interpretar tais documentos significa analisar que, para além de sua objetividade, expressa em sua estrutura argumentativa, todo documento, ao mesmo tempo em que revela, silencia, sinaliza, torna opacas outras expressões (GOUVÊAA, 2007, p.22).

Buscou-se, então, mapear as práticas e os discursos presentes nos documentos para, a partir daí, estabelecer relações com aspectos do contexto mais Rev. Caminhos da Educação: diálogos, culturas e diversidades, Teresina, v. 2, n. 1, p. 26-43, jan./abr. 2020 
amplo, o qual tinha a civilização da sociedade e, em especial, das crianças, por meio da escolarização, como um projeto da modernidade (BOTO, 2003; VEIGA, 2019; FARIA FILHO, 2014).

A análise tomou como base os debates teórico/metodológicos acerca da cultura escolar (FELGUEIRAS, 2010; VIDAL, 2010 e CHARTIER, 2009), que mostram como a organização do tempo e do espaço agiu no sentido de remodelar comportamentos, formar o caráter, passando por uma disciplina do corpo e direcionamento das consciências; e da forma escolar de socialização (JULIA, 2001; VINCENT, 1994) que, por sua vez, traduz esse lugar de aprendizagem de saberes e de inculcação de comportamentos e de habitus, sob o controle do Estado.

\section{A infância e o processo de escolarização no período de transição do Império para a República}

A historiografia analisada indicou que as iniciativas voltadas para atender a infância intensificaram-se no final do século XIX, demonstrando que a assistência vinculada à escolarização, no período republicano, assumiu configurações distintas da que encontramos no Império.

Os estudos do final do século XX, a exemplo de Rizzini (1997), Abreu (1997) e Martinez e Abreu (1997) apontaram que as proposições, projetos, medidas e instituições voltadas para as crianças, a partir do final do século XIX, tinham como preocupação reorganizar as relações de trabalho e a integração à ordem senhorial dos chamados "ingênuos", filhos ou filhas de pessoas escravizadas, nascidos após a lei do ventre livre, bem como a educação das classes populares nas décadas seguintes. Essa mudança levou o tema aos cernes das discussões sobre a assistência e escolarização da infância, mobilizando diversos setores da sociedade. 
A ênfase maior sobre a criança a tornou um instrumento de intervenção do Estado tanto na família como na sociedade. A criança passou a ser percebida como valioso patrimônio de uma nação, um ser em formação 'dúctil e moldável' e que, portanto, poderia ser transformado em elemento útil para o progresso da nação ou em um degenerado e inútil, a pesar nos cofres públicos (RIZZINI, 1997).

Concomitantemente, foi se reforçando a representação de que a construção de instituições específicas para formação das crianças era imprescindível a uma ação mais eficaz do que as outras estruturas sociais de formação e socialização, como a família e a Igreja (FARIA FILHO e VIDAL, 2000).

A afirmação da necessidade de gestar novas instituições, que tinham a questão da infância como o seu principal pilar, representava a sustentação dos saberes jurídicos, médicos e religiosos no controle e elaboração de políticas educacionais e assistenciais, como apontam também estudos mais recentes, como o de Kuhlmann Junior (2015).

Uma nova sociedade, que se queria moderna e republicana, assistiu o emergir de uma nova criança, que conquistou vários espaços: seja nas ruas, nas instituições ou mesmo na literatura. Instaurou-se a necessidade das escolas, abrangendo os vários locais de aprendizado, que assumiram um papel importante na difusão dos hábitos de higiene ou da nova sociabilidade de convívio e educação para a vida pública. A forma escolar, tal como ela emergiu no mundo moderno, traduziu não somente um lugar de aprendizagem de saberes, mas também:

“(...) como um lugar de inculcação de comportamento e de habitus que exige uma ciência de governo transcendendo e dirigindo, segundo sua própria finalidade, tanto a formação cristã como as aprendizagens disciplinares (...) A cultura escolar desemboca aqui no remodelamento dos comportamentos, na profunda formação do caráter e das almas que passa por uma disciplina do corpo e por uma direção das consciências (JULIA, 2001, p. 22).

A forma escolar de socialização, segundo Vincent (1994) é garantida por meio da ordenação do espaço, facilitando o controle pelo professor, na medida em que é graduada, dividida por séries, por idades, com exames regulares, que avaliam 
Acriança e o menor: a escolarização das crianças sob tutela do Estado, em Juiz de Fora/MG (1888-1916)

sistematicamente graus de aprendizado, como também facilita o controle dos estudantes uns sobre os outros, ao passo que também dificulta sua interação. O tempo também passa a ser ordenado pelo relógio e o ritmo deve ser simultâneo, ou seja, "todos os alunos aprendendo, na mesma proporção, as mesmas matérias" (BOTO, 2003, p.386). Logo, a formação da cidadania não é apenas uma questão de princípios e de valores. Ela procede, sobretudo, de uma forma escolar (DUBET, 2011).

Diante disso, o grande desafio, como nos aponta Chartier (2009), é pensar como os atores sociais dão sentido às suas práticas e aos seus enunciados, considerando a tensão entre as capacidades inventivas dos indivíduos ou das comunidades e as restrições e as convenções que os limitam, conforme a posição que ocupam nas relações que estabelecem.

Oliveira (2012), ao analisar as medidas e ações implementadoras do social em Juiz de Fora, a partir de metade do século XIX, apontou que o processo de gestão de novas escolas naquele contexto foi penetrado pela Igreja, através de relações que se estabeleceram por meio de obras de caridade, entre associações, congregações e o poder público. O estudo demonstrou que as tensões e disputas em torno da escolarização e da assistência à infância se deram em decorrência da expansão de outras instituições de origem religiosa, para além das católicas, as quais despontaram no município, no início do século XX. Ainda assim, mesmo após a secularização, percebeu-se a manutenção de uma estreita aliança entre a Igreja católica e o poder público local na manutenção deste setor.

Desse modo, a autora constatou que apesar da mudança ocorrida no final do Império em relação à concepção de infância, o modelo caritativo de assistência religiosa permaneceu na República, coexistindo com outras iniciativas da sociedade civil, pensadas e constituídas por médicos, governantes e juristas. 
Essas iniciativas, contudo, convergiam no sentido de buscar uma forma escolar universalizada, em que havia uma demanda de maior controle e civilização dos comportamentos, gerando a necessidade de racionalização e homogeneização de costumes de modo institucionalizado.

A homogeneidade decorrente desse modelo, segundo Greive (2019), foi fundamental para a produção e consolidação de desqualificações e exclusões, uma vez que não seguir esse modelo ou tê-lo precariamente, quando não se criaram condições para todas as crianças frequentarem escolas, produziu o estereótipo de pessoas incivilizadas e ignorantes.

A fim de contribuir com novas possibilidades de análise sobre como se deu esse processo de exclusão, realizamos um recorte dos casos de tutela e curatela, referentes às crianças órfãs do município de Juiz de Fora (1888-1916), buscando identificar quem eram essas crianças, qual era o lugar reservado a elas, qual o modelo de escolarização proposto e qual concepção de educação e de infância permeava os discursos dos sujeitos retratados na documentação.

\section{A maioridade e a tutela dos órfãos segundo a legislação}

Diante da ampliação do processo de escolarização das crianças no período inicial da República, a análise dos casos de tutela e curatela, correspondentes ao período de 1888 a 1916, teve como questão norteadora as políticas existentes em torno da assistência à infância, vinculadas à escolaridade das crianças sob tutela do Estado.

A partir do contexto da cidade de Juiz de Fora, buscou-se perceber, nas fontes, a configuração apresentada localmente para, então, pensar o encaixe desta realidade no âmbito nacional, sobre como as crianças "pobres", "abandonadas" e “órfãs”, então abordadas pela historiografia, eram vistas pelo poder público.

A instrução efetivamente parece ter sido um dos principais meios para atender à "nova" infância abandonada ou que vivia nas ruas, como se percebe tanto através das iniciativas de religiosos, da sociedade civil, como também dos governantes, no início do século XX. A criança, que passou a receber um grande Rev. Caminhos da Educação: diálogos, culturas e diversidades, Teresina, v. 2, n. 1, p. 26-43, jan./abr. 2020 
destaque na sociedade brasileira, já existia, mas a urbanização jogou sobre ela um olhar de preocupação e a instrução foi um importante meio de conter essa realidade.

Ao retomarmos a legislação que trata da questão da maioridade, naquele período, constatamos que durante o período de 1830 a 1917, no que se refere à regulamentação de órfãos, foi fixada a idade de 25 anos para administrar bens herdados. E, a partir da promulgação do Código Civil Brasileiro, em 1917, essa idade passou para 21 anos.

A questão da idade, como indicado por Veiga (1997, p.47), era fator determinante para o tipo de criação que se daria aos órfãos. A criação de órfãos "possuía algumas discriminações de idades de acordo com as distinções entre os possuidores de bens e os pobres, bem como os oriundos de legítimo casamento e filhos ilegítimos".

A autora ressalta ainda que a lei reconhecia como órfãos somente o (a) filho (a) cujo pai falecera e se orientava por esta premissa. As crianças que não eram de legítimo casamento, filhos de homens solteiros ou casados, seriam criadas à custa dos bens deixados pelos pais, e na ausência da mãe, pelos parentes. No caso de crianças filhas de religiosos ou de mulheres que assumiram segundas núpcias, seriam as crianças criadas à custa das câmaras municipais, de hospitais ou albergarias, destinadas à criação de "enjeitados".

Essas diferenciações, de acordo com Rizzini (1997), acarretaram uma dicotomia em relação à utilização do termo "criança", que se restringiu àquelas mantidas sob os cuidados da família, para a qual era reservada a cidadania, enquanto o termo "menor" foi utilizado para designar as que ficavam sob tutela do Estado, sendo objeto de leis e medidas educativas, assistencialistas e/ou disciplinadoras.

Costa (2005), por sua vez, faz uma distinção entre o termo "menor", que se refere às crianças moralmente abandonadas e potencialmente marginais, e "infância", usado para denominar as crianças pobres. 
Contudo, nas nomeações de tutores para os órfãos, em Juiz de Fora/MG, constatou-se que o termo "menor" apareceu frequentemente nos casos de tutela e curatela, para designar todos os órfãos sob tutela do Estado, ou seja, aqueles que ainda não atingiram a emancipação, a idade de 25 anos. O Juiz de órfãos usou o termo menor, indistintamente do estado de abandono pelos pais ou da morte dos mesmos, bem como da origem social e condição econômica das famílias das crianças sob sua tutela, demonstrando, ainda, a preocupação em "salvar" o menor.

Essa atenção dirigida à conduta moral dos menores, bem como com a instrução oferecida a eles demonstrou a influência do Estado e sua ação direta não apenas sobre a condução dos menores, mas também sobre suas famílias.

Ainda assim, os inventários dos casos de tutela e curatela e seus anexos foram fundamentais para a análise sobre a educação que foi destinada às crianças órfãs no início da República, em Juiz de Fora, pois permitiu observar as relações existentes entre tutor - órfão - Estado. Ainda que pese a questão moral, os documentos apontaram para a oferta de uma instrução diferenciada entre os órfãos ricos e pobres, indicando a distinção de políticas de escolarização existentes à época, para a infância, de modo geral, que se conformavam a sua origem e condição social e econômica.

Antes de adentrarmos na análise dos inventários, cabe ainda uma diferenciação entre os termos "tutela" e "curatela", pois, embora ambos se prestem ao papel de proteger, agir e tomar decisões em nome de outrem, a tutela, à qual nos deteremos a seguir, é um encargo atribuído por um juiz para que um adulto proteja, zele e administre os bens de um "menor", enquanto a curatela é atribuída àqueles que são judicialmente declarados incapazes, mesmo após atingirem a maioridade.

\section{A educação moral dos menores sob tutela}

A preocupação do Estado com a conduta moral das famílias, especialmente das mães e dos tutores dos menores, principais responsáveis pela educação dos órfãos nomeados pelo Juiz de órfãos, no município de Juiz de Fora, foi observada nos casos de tutela e curatela encontrados no Arquivo Municipal de Juiz de Fora, Rev. Caminhos da Educação: diálogos, culturas e diversidades, Teresina, v. 2, n. 1, p. 26-43, jan./abr. 2020 
A criança e o menor: a escolarização das crianças sob tutela do Estado, em Juiz de Fora/MG (1888-1916)

referentes ao período de 1888 a 1916, período que precede a criação do Código Civil Brasileiro, de 1917.

Tem-se como exemplo a tutela avulsa da menor Elisa Neves que, em 1913, apresentava-se com 12 anos de idade. De acordo com o escrivão: "A preta Maria Augusta deixou a filha Elisa e um filho de um ano incompleto de nome Edison e doente", além de ser "mãe de maus costumes, embriaga-se constantemente e abandonou os dois filhos. Prostituta, não convém que a mesma fique em sua companhia" (Casos de tutela..., 1913).

A descrição de Maria Augusta, mãe de Eliza, ajudou-nos a refletir sobre como modos e comportamentos específicos eram previstos, especialmente, em relação às mulheres, na medida em que a presença, circulação e atuação destas se davam nas figurações familiares, direcionando-as para o espaço doméstico.

A mesma rigidez em relação à restrição moral não se percebeu, contudo, em relação aos tutores do sexo masculino, chegando mesmo a evidenciar uma relação estreita entre a condição moral e a influência e poder econômico do tutor. É o que demonstrou o caso da renovação de tutela, em 1889, da menor Cleonice Pinto Cardozo, de 3 anos de idade, em que sua mãe, desentendendo-se com o tutor da filha, disputava a tutela da mesma, sob a seguinte alegação:

(...) tem contra si a circunstância de viver amasiado com a avó da órfã, o que é de importância capital visto se tratar de uma criança do sexo feminino, que em semelhante meio não pode receber salutares princípios de uma moral pura e sã indispensáveis à educação de uma moça (...) (Casos de tutela...,1889).

Apesar da argumentação de cunho moral e das várias apelações da mãe, o juiz decidiu por manter a tutela sob a guarda do tutor, por se tratar de "homem rico, influente e respeitado pela sociedade juiz-forana" (Casos de tutela...,1889). O tutor 
era ainda cidadão português, questão que foi desconsiderada pelo juiz de órfãos, tendo em vista que a lei de $1890, \S 1^{\circ}$, art. 148 - Direito da família -, proibia conferir tutela aos estrangeiros.

Fica evidente nestes dois casos de tutela que o controle moral estava destinado especialmente à população pobre, embora o termo menor fosse utilizado pelo Juiz de órfãos para designar as crianças sob tutela, independentemente da condição financeira das famílias.

O caso de tutela, de 1911, do menor Ulysses e de seus irmãos: Maria da Glória, Alina e Alberto, filhos de Dona Josephina Rodrigues Coelho e do finado Dr. Theóphilo Affonso Rodrigues evidencia que a condição de uma mãe de criar o próprio filho, no caso das famílias mais abastadas, era negada apenas quando a mãe passava às segundas núpcias, não podendo mais continuar a administrar os bens dos filhos, conforme definido na lei de 24 de janeiro de 1890, art. 94. Neste caso específico, a mãe foi nomeada tutora do menor Ulysses e as duas filhas já se encontravam casadas. Cabe ressaltar ainda que, neste caso, o menor era do sexo masculino.

Ao contrário das famílias abastadas, como fica evidente neste último caso, as famílias dos setores populares, quase sempre apareciam associadas à ignorância, pobreza, descuido, vício, abandono, licenciosidade, e, muitas vezes, vistas como criadoras de criminosos e delinquentes, sendo acusadas de incapazes, no que diz respeito à educação e à formação de suas crianças. A título de exemplo, temos outro caso de tutela, o de Maria, filha de Luduvina, liberta, em 1891. Segundo o juiz, tendo sua mãe uma vida irregular, para evitar que a dita menor se converta, indicou como tutor o cidadão Virgílio Franklin, que era idôneo.

Outro caso que coloca em foco a preocupação com a conduta moral de uma menor, é o de Delphina, de 13 anos, filha da liberta Paulina, dado em 1891, onde se tem a preocupação de garantir o futuro da referida menor, recebendo educação condigna e compatível com a sua pessoa.

Embora o objetivo deste estudo não tenha sido discutir a relação entre os senhores de escravos e as crianças recém libertas pela lei do Ventre Livre (1971), não se pode desconsiderar a questão da manutenção dos "ingênuos" sob a tutela de Rev. Caminhos da Educação: diálogos, culturas e diversidades, Teresina, v. 2, n. 1, p. 26-43, jan./abr. 2020 
seus "ex-senhores", sob a forma de soldada, em que estes teriam a obrigação de criá-los e educá-los até a idade de 8 anos, quando poderiam então escolher entre receber do estado uma indenização de 600 mil réis em títulos de 30 anos a $6 \%$ ou usarem o trabalho dos menores até os 21 anos. Caso recebesse as crianças, o Estado poderia enviá-las para serem abrigadas em asilos e em instituições de caráter filantrópico e educativo. Veiga (2007) revela que essa prática era frequente, sobretudo, nos dez primeiros anos da República.

O fato que explica a frequência dessa situação é que tanto os órfãos pobres, que seriam criados à custa dos bens deixados pelos pais, quanto os que ficavam à custa das Câmaras, poderiam a partir dos 7 anos serem dados por soldada. De acordo com Veiga (2007), isso significava que aqueles que os criassem, mesmo as mães, comprometiam-se a mantê-los com moradia, alimentos, vestimentas, instrução, em troca de serviços prestados pelo órfão dos 7 aos 12 anos. Portanto, a maioria dos "ingênuos" permanecia nas próprias fazendas.

Os casos de tutela analisados trazem, portanto, uma parte da história de um cotidiano (FELGUEIRAS, 2010) no qual, como afirma Freitas (2016), "fez diferença para cada criança a impregnação das desigualdades sociais nos contornos de sua existência".

\section{As distintas propostas de instrução para os menores}

O tipo de instrução que seria ofertada aos menores era delegado pelo Juiz de Órfãos como de responsabilidade dos tutores nomeados por ele. A distinção da instrução escolar a ser oferecida se daria em conformidade com a condição financeira da família do menor, como explicita a seguinte fala do Juiz de órfãos, Francisco Augusto dos Santos, em 1911: “Intime-se o tutor nomeado para prestar juramento e tomar posse dos menores e administrar-lhes os bens deles, digo, bens Rev. Caminhos da Educação: diálogos, culturas e diversidades, Teresina, v. 2, n. 1, p. 26-43, jan./abr. 2020 
deste, que serão educados conforme a posse deles e a posição que na sociedade ocupou o seu genitor" (Casos de tutela ...,1911).

A distinção social demarcada por meio da instrução escolar é demonstrada em diversos outros casos de tutela, legitimando a distinção entre a educação de ricos e pobres. No caso da tutela da menor Josephina de Mattos Lemos, de 10 anos, filha de mãe falecida e pai desconhecido, o tutor ficou obrigado a educá-la, alimentá-la e vesti-la e a mais obrigações do estilo, especialmente a colocar a referida menor no Asilo João Emílio, situado na cidade de Juiz de Fora.

Este asilo foi implementado como um recolhimento para órfãs e inaugurado em 1895, sob a iniciativa do Padre João Emílio. Com sua morte, a instituição foi entregue à Congregação Bom Pastor, em 1902. De acordo com o relato da Irmã Maria da S. F. Xavier Nóvoa, em 1905, “a instituição possuía 72 órfãs e 11 funcionários e, em 1910, 60 órfãs e 40 moças penitentes” (apud FILHO, 1987, p.1831).

De acordo com Moreira (2008), a educação escolar, principalmente quando os órfãos eram pobres, era voltada para a educação para o trabalho. O procedimento utilizado era o encaminhamento dos órfãos a um mestre de ofício que lhe ensinaria uma profissão, embora eventualmente elas também fossem levadas a aprender a ler, escrever e contar. Os casos de tutela de menores de origem social abastada, entretanto, apontam outro destino, bem como outro tipo de educação para os mesmos, visto que a instrução se dava em colégios particulares, do tipo externato ou semi-internato, de origem religiosa.

No detalhamento da prestação de contas dos tutores, referente aos menores que possuíam bens a serem administrados, foram localizadas informações sobre o comportamento e habilidades dos órfãos, bem como sobre seus rendimentos, os quais vinham acompanhados de notas fiscais referentes às despesas dos tutores com os menores.

Como exemplo, apresentamos a descrição realizada em 1890 pelo padrasto dos órfãos: Antônio, José e Joaquim Gomes, filhos do finado Antonio Gomes da Silveira, na qual ele declarou ao juiz de órfãos onde viviam, seus temperamentos, idades, estados de saúde e qual a educação que estava sendo destinada aos menores: 
1) Órfão Antonio Gomes da Silveira - tem bom comportamento, sabe ler e escrever, sabe as 4 operações, algumas noções de aritmética, esteve nos Colégios do Dr. Cavalcante, do Dr. Hermes e Padre Café, nos quais procurei por todos os meios possíveis dar-lhe uma educação mais elevada, mas não pode conseguir, porque sua vocação era para o trabalho, no qual tem mostrado muita aptidão e inteligência, está no oficio de carpinteiro e muito adiantado. Mora em companhia do padrasto. 4:200\$000.

2) (...) órfão José Gomes da Silveira é um pouco áspero de gênero, entrou nos Collegios, está no ofício de marceneiro, sabe ler e escrever e as 4 operações, é muito doente, sofre de asma, mora com o padrasto. 4:200\$000.

3) Joaquim Gomes da Silveira é genioso e travesso, mas ativo, sabe ler e escrever muito bem e as 4 operações, sofre de fluxo asmático; noções de aritmética e está continuando no estudo, mora em companhia de sua mãe e do padrasto. 4:200\$000.

A alegação do tutor de que os órfãos não se adequaram à educação considerada por ele "mais elevada", sob o pretexto de que não dispunham de vocação para os estudos, mas para o trabalho, reforça a dicotomia existente entre trabalho manual e intelectual, bem como a hierarquia existente entre estes dois saberes. Aponta ainda que embora o conhecimento da gramática escolar não fizesse parte apenas da cultura do homem culto, como referendado por Chervel (apud BOTO, 2003), frequentar a escola, aprender a contar, ler e escrever, cuidar da saúde, passar a infância nos bancos escolares, tornou-se um padrão de civilização (GREIVE, 2019), como também passou a ser aspirado como modelo de distinção social.

Os documentos apontam ainda para uma educação diferenciada entre os sexos. Às meninas coube aprender a tecer, fiar e coser, enquanto os meninos eram 
encaminhados para os mestres de ofícios mecânicos, tais como: de alfaiate, sapateiro, barbeiro, e ainda, aprendiam a ler, escrever e contar.

Semelhante, porém, é a influência das instituições religiosas na instrução dos órfãos, sejam eles pobres, através dos asilos de tipo internato, ou ricos, através de colégios do tipo externato. Fato que é mostrado por Irene Rizzini (1997), ao analisar a legislação sobre a assistência à infância, a partir de metade do século XIX. A autora aponta que esta é penetrada pela administração das instituições asilares de origem religiosa, através das alianças que se estabeleciam entre as obras de caridade e o governo. E ainda, que a responsabilidade de zelar pelas crianças "expostas" era da Igreja, na esfera jurídica e política, situação que perdurou também durante a República, em relação às crianças órfãs, ou seja, aos menores alvos da ação e tutela do Estado.

\section{Considerações finais}

A partir das análises realizadas percebe-se que o Estado delegava aos tutores o papel de dar às crianças órfãs instrução condizente com as posses da família do menor, apesar da preocupação com o controle da conduta moral, principalmente das famílias pobres e das crianças do sexo feminino.

Os casos de tutela referentes ao final do século XIX, indicaram que após a abolição da escravidão no Brasil, principalmente as mulheres negras foram associadas à pobreza, descuido, vício, abandono, licenciosidade, e, portanto, potencialmente incapazes de educar seus filhos. Cabe ressaltar que muitas vezes, estes eram tidos como órfãos, pois os fazendeiros não os reconheciam como filhos legítimos, e ainda se beneficiavam dos trabalhos dos menores por meio da soldada e de indenizações do Estado.

Moreira (2008) nos alerta para o fato de que em Minas Gerais a preocupação das autoridades em relação aos órfãos e expostos foi reforçada pela peculiar situação que envolvia parcela numerosa da população, constituída de mestiços pobres e livres, que, na visão dessas autoridades, eram potencialmente perigosos para a ordem pública, sendo necessário educá-los para se tornarem úteis à sociedade. 
O estudo do conjunto de documentos analisados, aproximadamente 20 casos de tutela, que se deram no período de 1888 a 1916, ajudou-nos a perceber como se dava a mediação entre tutor, família e Estado, bem como era a atuação deste em relação à garantia da instrução e do controle das condutas das famílias dos menores.

Esse trabalho possibilitou, em certa medida, a compreensão da dinâmica das práticas educativas no cotidiano da sociedade na Primeira República, momento em que a ação do poder público se mostrou insuficiente em relação à assistência à infância pobre, privilegiando a política de subsidiar instituições particulares que assistissem aos menores sob sua tutela, ao invés de buscar criar instituições públicas de assistência.

O diálogo com as fontes possibilitou problematizar as representações que temos delas como também da própria pesquisa histórica. A partir da perspectiva que considera a infância como categoria de análise, dando visibilidade aos órfãos, foi possível perceber que o destino destas crianças não era uniforme, demonstrando manifestações de poderes desiguais entre homens e mulheres e entre as distintas classes sociais. Também os discursos normativos e as práticas educacionais indicaram distintos modelos de educação familiar das crianças, bem como trouxeram alguns apontamentos sobre seu cotidiano.

\section{Referências}

ABREU, Martha. Mães escravas e filhos libertos: novas perspectivas em torno da lei do Ventre Livre. In: In: RIZZINI, Irene. (Org.). Olhares sobre a criança no Brasil: séculos XIX e XX. Rio de Janeiro: Petrobrás-BR: Ministério da Cultura: USU Ed. Universitária: Amais, 1997. 
BOTO, C. A civilização escolar como projeto político e pedagógico da modernidade: cultura em classes, por escrito. In: Cad. Cedes, v. 23, n. 61. Campinas, dez, 2003, p. 378-397. Disponível em: http://www.cedes.unicamp.br. Acesso em 10.09. 2014.

CASOS de tutela e curatela (1888-1916). Arquivo Público Municipal de Juiz de Fora.

CHARTIER, Roger. A bistória ou a leitura do tempo. Belo Horizonte: Autêntica Editora, 2009.

DUBET, François. Mutações cruzadas: a cidadania e a escola. Revista Brasileira de História da educação. v.16, n.47, mai-ago, 2011.

FARIA FILHO, L. M \& VIDAL, D. G. Os tempos e os espaços escolares no processo de institucionalização da escola primária no Brasil. In: Revista Brasileira de Educação, n. 14. Mai/Jun/Jul/Ago, 2000, p.19-34.

FELGUEIRAS, Margarida Louro. Cultura escolar: da migração do conceito à sua objectivação histórica. In: FELGUEIRAS, Margarida Louro; VIEIRA, Carlos Eduardo (Eds.) Cultura escolar, migrações e cidadania. Porto: Sociedade Portuguesa de Ciências da Educação e autores, 2010, p. 17-32.

FILHO, José Procópio Teixeira. Assistência Social em Juiz de Fora. In: Revista do Instituto Histórico Geográfico Brasileiro. JF: IHGB, ano IV, n.4, jun, 1968, p.18-31.

FREITAS, Marcos C. (org.). História social da infância no Brasil. 9 ed. São Paulo: Cortez, 2016.

GREIVE, C. G. Escola pública, processo civilizador, modernidade eurocêntrica e exclusão sociorracial: diálogos com Anibal Quijano e Norbert Elias. In: VEIGA, Chyntia Greive. OLIVEIRA, Marcus Aurélio Taborda de. (Org) Historiografia da educação: abordagens teóricas e metodológicas. Fino Traço, 2019.

JULIA, Dominique. A cultura escolar como objeto histórico. In: Revista Brasileira de História da Educaşão. Campinas: Editora Autores Associados, n¹, Janeiro/Junho. 2001, p. 9-43.

KUHLMANN JR, Moysés. Infância e educação infantil: uma abordagem histórica. 7ed.Porto Alegre: Mediação, 2015.

OLIVEIRA, Paloma Rezende de. Vinde a mim os pequeninos: políticas de educação e assistência às infâncias. Juiz de Fora: Funalfa, 2012.

MARTINEZ, Alessandra Frota e ABREU, Martha. Olhares sobre a criança no Brasil: Perspectivas históricas. In: Olhares sobre a criança no Brasil: século XIX e XX. (Org.) Irene Rizzini. Rio de Janeiro: Petrobrás-BR: Ministério da Cultura: USU Ed. Universitária: Amais, 1997.

MOREIRA, Aleana Jota. Aprendizado de ofício e/ou de primeiras letras na comarca do Rio das Velhas: conforme a lei determinava ou a vontade dos pais? In: Anais da Anped Regional de Belo Horizonte. 2008.

RIZZINI, Irma. Principais temas abordados pela literatura especializada sobre infância e adolescência: séculos XIX e XX. In: RIZZINI, Irene. (Org) Olhares sobre a criança no Brasil: 
A criança e o menor: a escolarização das crianças sob tutela do Estado, em Juiz de Fora/MG (1888-1916)

séculos XIX e XX. Rio de Janeiro: Petrobrás-BR: Ministério da Cultura: USU Ed. Universitária: Amais, 1997. p.39-77.

VEIGA, Cynthia Greive. Cultura escrita: representações da criança e o imaginário de infância. Brasil, século XIX. In: LOPES, Alberto et all (org). Para a compreensão histórica da infância. Belo Horizonte: Autêntica, 2007.

VIDAL, Diana G; SCHWARTZ, Cleonara M. Sobre Cultura Escolar e História da Educação: questões para debate. IN: VIDAL, Diana G; SCHWARTZ, Cleonara M. História das Culturas Escolares no Brasil (orgs.). Vitória: EDUFES, 2010, p. 13-35.

VINCENT, G.; LAHIRE, B.; THIN, D. Sur l'histoire et la théorie de la forme scolaire. In: VINCENT, GUY (Org.) L'Éducation prisonnière de la forme scolaire? Scolarisation et socialisation dans les societies industrielles. Lyon: Presses Universitaires de Lyon, 1994, p.11-48. 